\title{
Alterations of Respiratory Systems in Aspergillus niger under the Conditions of Citric Acid Fermentation
}

\author{
Kohtaro Kirimura, Yuji Hirowatari and Shoji Usami \\ Department of Applied Chemistry, School of Science and Engineering, \\ Waseda University, Shinjuku-ku, Tokyo 160, Japan
}

Received September 8, 1986

\begin{abstract}
Under the conditions of citric acid fermentation, Aspergillus niger WU-2223L possessed at least two respiratory systems. One system was sensitive to cyanide $(\mathrm{CN})$ and the other was sensitive to salicylhydroxamic acid (SHAM). The respiration of mycelia was partially inhibited by $\mathrm{CN}$ or SHAM, and was completely inhibited in the presence of both CN and SHAM. With culture time, the $\mathrm{CN}$-sensitivity of respiration decreased and the SHAM-sensitivity increased. The respiratory rate itself decreased suddenly at 4 days and thereafter remained at a low level. The SHAM-sensitive respiration was localized in the mitochondria. The alterations of respiration in the mitochondria were similar to those observed in mycelial cells.
\end{abstract}

It has been shown that many higher plants and eucaryotic microorganisms respire genetically or environmentally by means of two respiratory systems. ${ }^{1 \sim 3)}$ The normal system is a cytochrome chain, that is sensitive to cyanide (CN) and antimycin A. The alternative one is insensitive to these inhibitors but sensitive to salicylhydroxamic acid (SHAM). The two respiratory systems are commonly accepted to compete for reducing equivalents on the oxygen side of dehydrogenases, forming a branched electron transport system (see Fig. 3). $\left.{ }^{1} \sim 5\right)$

Zehentgruber et $a l^{6)}$ reported that the respiration of Aspergillus niger proceeds via a cytochrome chain and a SHAM-sensitive alternative system. Kubicek et al. ${ }^{7)}$ reported that citric acid production by $A$. niger is strongly inhibited by SHAM during the early-log-phase whereas growth is not. These observations suggest that participation of SHAM-sensitive respiration in citric acid production by $A$. niger.

We have studied citric acid fermentation by $A$. niger WU-2223L, and previously reported that mycelial respiration and acid productivity are influenced markedly by the culture medium constituents. ${ }^{8)}$ This paper reports that the SHAM-sensitivity of respiration in $A$. niger WU-2223L increased and the $\mathrm{CN}$-sensitivity decreased during citric acid fermentation, probably resulting from changes in the capacities of these respiratory systems in mitochondria.

\section{MATERIALS AND METHODS}

Microorganism and culture conditions. Aspergillus niger WU-2223L, ${ }^{8)}$ a good producer of citric acid, was used. Conidia of the strain were suspended in $60 \mathrm{ml}$ of a synthetic medium at a concentration of $1 \times 10^{6} / \mathrm{ml}$ and then cultivated aerobically with shaking $(120 \mathrm{rpm})$ in Sakaguchi flasks $(500 \mathrm{ml})$ at $30^{\circ} \mathrm{C}$. The synthetic medium contained (per liter of distilled water): glucose, $120 \mathrm{~g}$; $\left(\mathrm{NH}_{4}\right)_{2} \mathrm{SO}_{4}, 3 \mathrm{~g}$; $\mathrm{K}_{2} \mathrm{HPO}_{4}, 1 \mathrm{~g} ; \mathrm{KH}_{2} \mathrm{PO}_{4}, 1 \mathrm{~g} ; \mathrm{MgSO}_{4} \cdot 7 \mathrm{H}_{2} \mathrm{O}, 0.5 \mathrm{~g} ; \mathrm{MnSO}_{4}$, $14 \mathrm{mg} ; \mathrm{FeCl}_{3} \cdot 6 \mathrm{H}_{2} \mathrm{O}, 10 \mathrm{mg}$; and $2 \%(\mathrm{v} / \mathrm{v})$ methanol. The $\mathrm{pH}$ was initially adjusted to 3.0 . Methanol promotes citric acid production and is not used as a nutrient. ${ }^{8)}$

Isolation of mitochondria. The mitochondrial fraction (heavy particulate fraction) was prepared by the modified methods of Watson and Smith ${ }^{9)}$ and Uchiyama et al. ${ }^{10)}$ On an indicated culture day, mycelia were harvested on a Whatman GF/A filter with suction and then washed twice with a $0.7 \mathrm{M} \mathrm{KCl}$ solution. Portions of the washed mycelia ( $1 \mathrm{~g}$ wet weight) were suspended in $10 \mathrm{ml}$ of $50 \mathrm{~mm}$ potassium phosphate buffer, $\mathrm{pH} 6.0$, containing $15 \mathrm{mg}$ of chitinase (Godo Shusei Co., Tokyo), $80 \mathrm{mg}$ of hemicellulase (Miles Laboratories, Inc., Elkhart) and $0.7 \mathrm{M}$ $\mathrm{KCl}$. Each mixture was incubated at $30^{\circ} \mathrm{C}$ in an 
Erlenmeyer flask $(50 \mathrm{ml})$ for $90 \mathrm{~min}$ with gentle shaking $(60 \mathrm{rpm})$ and then centrifuged at $2,500 \times g$ for $20 \mathrm{~min}$ at $2^{\circ} \mathrm{C}$. The mycelia after enzymic pretreatment were suspended in $10 \mathrm{~mm}$ potassium phosphate buffer, $\mathrm{pH} 7.2$, containing $0.65 \mathrm{~m}$ sorbitol and $0.5 \mathrm{~mm}$ EDTA (SE buffer), homogenized in a teflon/glass homogenizer $(700 \mathrm{rpm})$ for $10 \mathrm{~min}$ at $2^{\circ} \mathrm{C}$, and then centrifuged at $3,000 \times g$ for $10 \mathrm{~min}$ at $2^{\circ} \mathrm{C}$. The precipitate was discarded and the supernatant was centrifuged at $20,000 \times g$ for $15 \mathrm{~min}$ at $2^{\circ} \mathrm{C}$. The sedimented pellet was resuspended in SE buffer and then centrifuged at $20,000 \times g$ for $15 \mathrm{~min}$ at $2^{\circ} \mathrm{C}$. The resulting pellet was used as the mitochondrial fraction. The latter was kept at $2^{\circ} \mathrm{C}$ and analyzed within $3 \mathrm{hr}$.

Measurement of respiration. The respiration of both mycelia and isolated mitochondria in temperaturecontrolled reaction chambers was monitored with a Clarktype electrode (Yellow Springs Instruments, Cleveland, Ohio) by a modification of the method of Dutton. ${ }^{11)}$ The respiration of mycelia was measured at $30^{\circ} \mathrm{C}$ in $3 \mathrm{ml}$ of a reaction mixture containing mycelia $(1.0 \mathrm{mg}$ dry weight/ $\mathrm{ml}$ ) and $0.5 \mathrm{M}$ glucose in $10 \mathrm{~mm}$ potassium phosphate buffer, $\mathrm{pH}$ 7.2. The respiration of mitochondria was measured at $25^{\circ} \mathrm{C}$ in $2.5 \mathrm{ml}$ of a reaction mixture containing mitochondria ( $4 \mathrm{mg}$ protein $/ \mathrm{ml}$ ), $0.4 \mathrm{M}$ mannitol, $0.5 \mathrm{~mm}$ EDTA, $10 \mathrm{~mm} \mathrm{KCl}$ and $2.5 \mathrm{mg} / \mathrm{ml}$ of bovine serum albumin (fraction V, Sigma) in $10 \mathrm{~mm}$ potassium phosphate buffer, pH 7.2. Respiration measurements for the mitochondria were performed at State $3 .{ }^{11)}$ Succinate, ADP, $\mathrm{KCN}$ and SHAM were added, injecting concentrated solution to give the final concentrations indicated in the footnotes to figures.

Analytical methods. The amount of citric acid in the culture broth was determined by the method of Möllering and Gruber, ${ }^{12)}$ and that of glucose by the Glucose-B-Test method (Wako Pure Chemical Ind., Tokyo). The weight of mycelia is expressed as that of the dried form. The protein content was determined by the method of Lowry et al. ${ }^{13)}$ with bovine serum albumin as a standard.

\section{RESULTS}

The time course of citric acid fermentation by $A$. niger WU-2223L is shown in Fig. 1 . The concentration of citric acid in the culture broth increased throughout the whole culture period (9 days). The dry weight of mycelia also increased during the initial 6 days. In this period, the growth of mycelia occurred in the culture broth even under low $\mathrm{pH}$ conditions (below 3.0). After 6 days, the dry weight of the mycelia did not increase. Therefore the amount of citric acid produced per dry weight

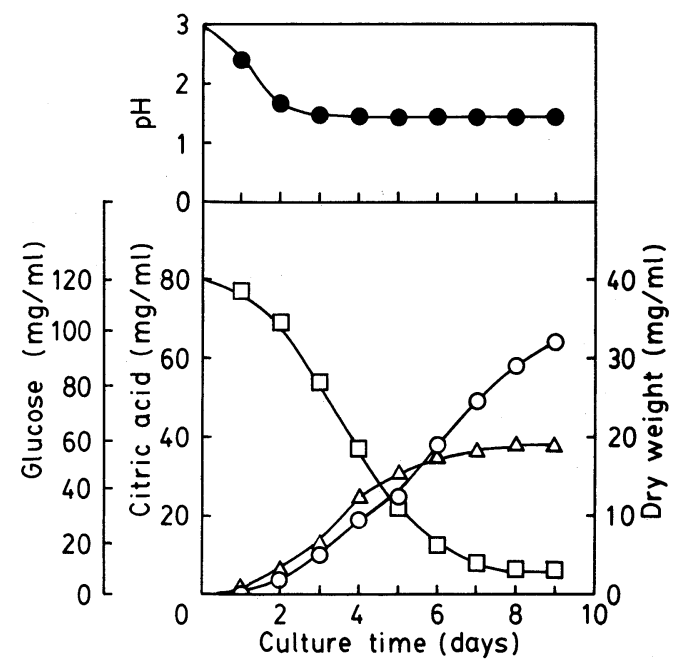

FIG. 1. Time Course of Citric Acid Fermentation by Aspergillus niger WU-2223L.

Symbols: citric acid $(\bigcirc)$, dry weight $(\triangle)$, glucose $(\square)$ and $\mathrm{pH}(\mathrm{O})$.

(A)

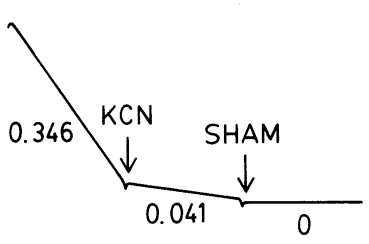

(B)
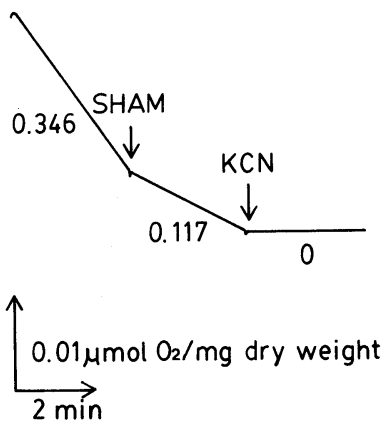

FIG. 2. Effects of $\mathrm{CN}$ and SHAM on the Mycelial Respiration of Aspergillus niger WU-2223L.

Mycelia at 5 days (at the late-log-phase) were used. At the points indicated by arrows, either $\mathrm{KCN}$ or SHAM was added to the reaction mixture to give final concentrations of $2.5 \mathrm{~mm}$ and $2.0 \mathrm{~mm}$, respectively. The values shown in the figure are the respiratory rates expressed in $\mu \mathrm{mol}$ $\mathrm{O}_{2} / \mathrm{hr} / \mathrm{mg}$ (dry weight). The rate of inhibition by $\mathrm{CN}$ alone was $88.3 \%$ (A) and that by SHAM alone was $66.0 \%$ (B). 
in this period was higher than that in the initial culture period.

The effects of $\mathrm{CN}$ and SHAM on the respiration of the mycelia at 5 days are shown in Fig. 2. The respiration was partially inhibited by $\mathrm{CN}$ or SHAM, and was completely inhibited in the presence of both $\mathrm{CN}$ and SHAM. These observations indicated that at least two respiratory systems, one $\mathrm{CN}$ sensitive and the other SHAM-sensitive, are present in the mycelia of $A$. niger WU-2223L. Additional experiments were performed using antimycin A, a respiratory inhibitor of a cytochrome chain (data not shown). Respiration of the mycelia at 5 days was partially inhibited by the addition of antimycin A, and subsequent addition of SHAM inhibited the respiration completely. In a parallel experiment, the respiration was also partially inhibited by the addition of SHAM, and subsequent addition of antimycin A resulted in complete inhibition. These results indicated that the antimycin A-insensitive respiration was inhibited by SHAM, exactly as in the case of the $\mathrm{CN}$-insensitive respiration (Fig. 2). Therefore, it was suggested that the $\mathrm{CN}$ - and antimycin A-sensitive respiratory system and the SHAMsensitive one form a branched electron transport system (Fig. 3), similar to those proposed for Neurospora crassa $^{4)}$ and higher plants. ${ }^{1 \sim 3)}$ It should be noted that the extents of the inhibition by $\mathrm{CN}$ alone (Fig. 2(A)) and by SHAM alone (Fig. 2(B)) were not additive. This suggested that the $\mathrm{CN}$-sensitive respi-

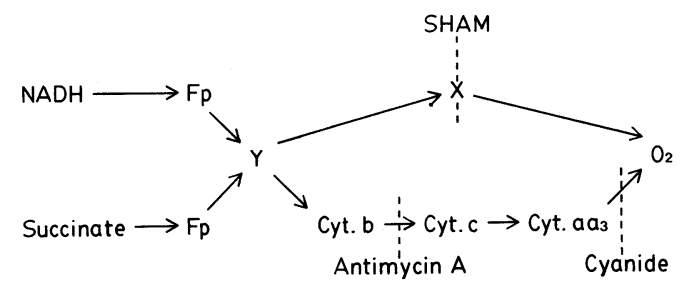

FIG. 3. Branched Electron Transport System.

$X$ denotes the antimycin A- and $\mathrm{CN}$-insensitive oxidase system, and $Y$ the hypothetical branch point, according to Lambowitz et al. ${ }^{4)}$ The sites of inhibition by drugs are indicated by dashed lines.

Cyt, cytochrome; Fp, flavoprotein. ratory system and the SHAM-sensitive one are correlated to each other.

The respiratory rates and the sensitivities to $\mathrm{CN}$ and SHAM of mycelia after various culture periods are shown in Fig. 4. The respiratory rate of mycelia decreased suddenly at 4 days and thereafter remained almost constant (Fig. 4(A)). The percent inhibition of respiration by $\mathrm{CN}$ or SHAM is shown in Fig. 4(B). During citric acid fermentation, SHAMsensitive respiration was observed regardless of the culture period. The $\mathrm{CN}$-sensitivity of the respiration decreased during the period between 5 days and 8 days (the late-log-phase and the beginning of the stationary phase, see Fig. 1), and the SHAM-sensitivity increased, especially after 4 days (the late-log-phase). These observations indicated that the role of

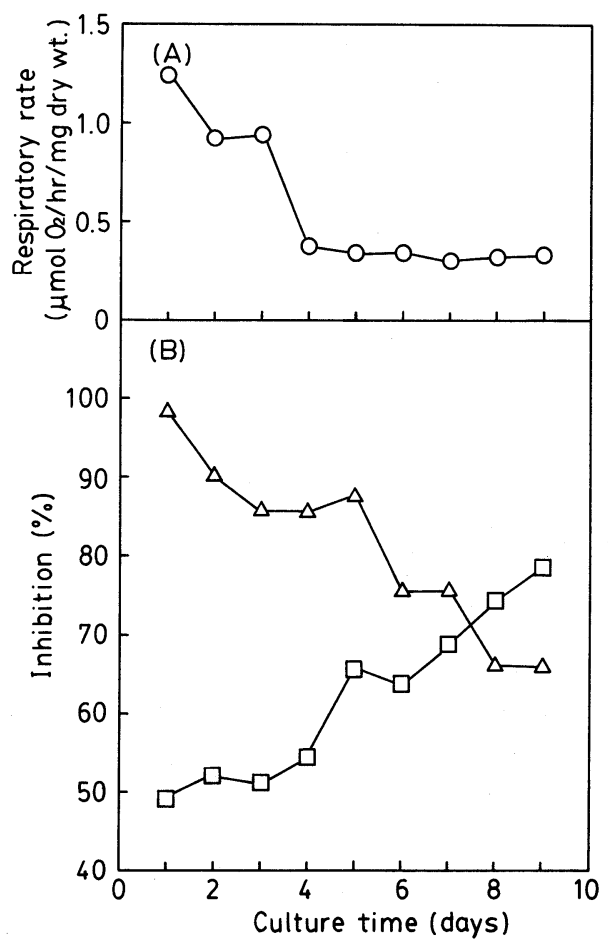

FIG. 4. Time Courses of the Respiratory Rate (A) and the Rates of Inhibition by CN or SHAM (B) in the Mycelia of Aspergillus niger WU-2223L.

In panel (B), the rates of inhibition are shown as the sensitivities of the mycelial respiration to $\mathrm{CN}(\triangle)$ and to SHAM ( $\square)$. The final concentrations of KCN and SHAM in the incubation mixture were the same as those in the footnote to Fig. 2. 


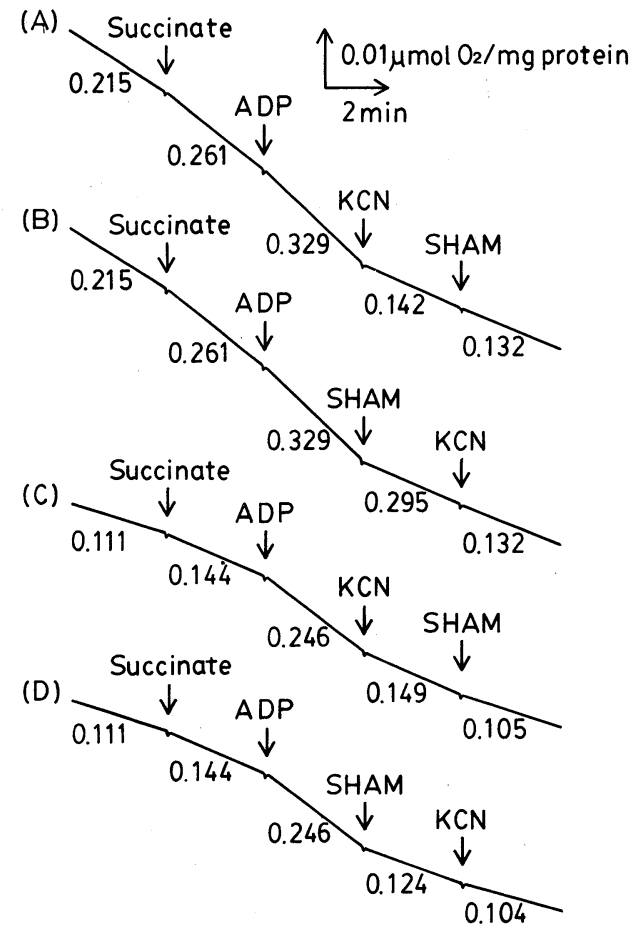

FIG. 5. Effects of CN and SHAM on the Respiration of Isolated Mitochondria of Aspergillus niger WU-2223L.

The rates of State 3 respiration in mitochondria isolated at 1 day (A) (B), and at 9 days (C) (D) of culture were examined. Without inhibitors, the respiration at State 3 was maintained for at least $12 \mathrm{~min}$ after the addition of ADP. At the points indicated by arrows, drugs were added to the reaction mixtures. The final drug concentrations were: succinate, $10 \mathrm{mM}$; ADP, $160 \mu \mathrm{M} ; \mathrm{KCN}, 2.5 \mathrm{~mm}$; SHAM, $2.0 \mathrm{~mm}$. The values shown in the figure are the respiratory rates expressed in $\mu \mathrm{mol} \mathrm{O} / \mathrm{hr} / \mathrm{mg}$ protein. The rates of inhibition by $\mathrm{CN}$ were $56.9 \%$ (A) and $39.5 \%$ (C). The rates of inhibition by SHAM were $10.9 \%$ (B) and $49.6 \%$ (D).

the SHAM-sensitive respiration became more greater in the mycelia with culture time.

Respiration of the mitochondria is shown in Fig. 5. The SHAM-sensitive respiration was found only in the mitochondrial fraction and no SHAM-sensitive respiration was detected any other fractions produced during the process of mitochondria isolation. The respiratory rate of the mitochondria isolated at 9 days was lower than that at 1 day. The respiration of mitochondria was partially inhibited by $\mathrm{CN}$ or SHAM. The SHAM-sensitivity of the respiration of mitochondria at 9 days was higher than that at 1 day, whereas the $\mathrm{CN}$-sensitivity at 9 days was lower than that at 1 day. The changes in respiration of mitochondria were similar to those observed in the case of mycelial cells, though the mitochondrial respiration was not completely blocked in the presence of both CN and SHAM. At present, it remains unknown whether or not mitochondria from $A$. niger WU-2223L contain $\mathrm{CN}$ and SHAM-insensitive respiratory system(s). However, these observations at least indicate that the capacity of the $\mathrm{CN}$-sensitive respiratory sytem decreased and that of the SHAMsensitive one increased during citric acid fermentation.

\section{DISCUSSION}

The nature of the SHAM-sensitive respiratory system remains poorly understood. There is, however, general agreement that it functions as a reoxidative system for $\mathrm{NADH}$ without ATP formation, ${ }^{1}$ 5,14,15) and the branch point from the cytochrome chain has been reported to be at the level of ubiquinone (see Fig. 3). ${ }^{14,15)}$ In N. crassa, ${ }^{4,5)}$ the SHAMsensitive respiratory system is induced when the cytochrome chain functions insufficiently due to mutation or inhibition of mitochondrial protein synthesis. In contrast, in Candida albicans $^{16)}$ or Histoplasma capsulatum, ${ }^{17)}$ the SHAM-sensitive respiratory system is constitutive. Zehentgruber et al. ${ }^{6)}$ reported that the SHAM-sensitive respiratory system in $A$. niger appears to be constitutive since it was present at all stages of culture under varying nutrient conditions.

In the present study, it was found that the SHAM-sensitivity of the respiration increased and the $\mathrm{CN}$-sensitivity decreased in both mycelial cells and mitochondria during citric acid fermentation by $A$. niger WU-2223L. The SHAM-sensitive respiration in $A$. niger exists in mitochondria, similar to in the cases of other eucaryotic cells. ${ }^{1 \sim 5,14,15)}$ The respiration of the isolated mitochondria exhibited higher sensitivity to SHAM at 9 days than at 1 day, whereas it exhibited higher sensitivity to $\mathrm{CN}$ at 
1 day than at 9 days. The respiratory rate of the mitochondria isolated at 9 days was lower than that at 1 day, similar to as observed for mycelial cells. These observations indicate that the low respiratory rate and the changes in the sensitivities of respiration to $\mathrm{CN}$ and SHAM in mycelial cells did not result from the regulation of respiration by some cytosolic factors but from changes in the capacities of the respiratory systems in mitochondria during citric acid fermentation.

We previously examined the changes in the activities of enzymes in the tricarboxylic acid (TCA) cycle of $A$. niger WU-2223L, and found that the specific activity of citrate synthase remained almost constant and those of such enzymes as isocitrate dehydrogenase decreased during the period of citric acid accumulation. ${ }^{8)}$ Similar results were obtained on solid fermentation with another $A$. niger strain. ${ }^{18)}$ From these results, we have concluded that citric acid accumulation is caused by decreases in the activities of enzymes, such as isocitrate dehydrogenase, in the TCA cycle with culture time. ${ }^{8,18)}$ It remains unclear whether or not the changes of respiratory systems are really correlated with citric acid production. It is likely, however, that the changes of respiratory systems are related to the unusual functioning of the TCA cycle during citric acid fermentation.

Acknowledgments. We wish to express our appreciation to Professor I. Yasumasu, Dr. A. Fujiwara and Dr. T. Hisahori (Department of Biology, School of Education, Waseda University) for their many valuable suggestions.

\section{REFERENCES}

1) M. F. Henry and E. J. Nyns, Sub. Cell. Biochem., 4, 1 (1975).

2) J. M. Palmer, Ann. Rev. Plant Physiol., 27, 133 (1976).

3) T. Solomons, Ann. Rev. Plant Physiol., 28, 279 (1977).

4) A. M. Lambowitz and C. W. Slayman, J. Bacteriol., 108, 1087 (1971).

5) D. L. Edwards and F. Kwiecinski, J. Bacteriol., 116, 610 (1973).

6) O. Zehentgruber, C. P. Kubicek and M. Röhr, FEMS Microbiol. Lett., 8, 71 (1980).

7) C. P. Kubicek, O. Zehentgruber, H. El-Kalak and M. Röhr, Eur. J. Appl. Microbiol. Biotechnol., 9, 101 (1980).

8) S. Usami, Mem. School Science \& Engineering Waseda Univ., 42, 17 (1978).

9) K. Watson and J. E. Smith, J. Bacteriol., 96, 1546 (1968).

10) H. Uchiyama, M. Ando, Y. Toyonaka and T. Tabuchi, Eur. J. Biochem., 125, 523 (1982).

11) P. L. Dutton, Biochim. Biophys. Acta, 226, 63 (1971).

12) H. Möllering and W. Gruber, Anal. Biochem., 17, 369 (1966).

13) O. H. Lowry, N. J. Rosebrough, A. L. Farr and R. J. Randall, J. Biol. Chem., 193, 265 (1951).

14) S. Huq and J. M. Palmer, "Plant Mitochondria," ed. by G. Ducet and C. Lance, Elsevier/North-Holland Biomedical Press, Amsterdam, 1978, p. 225.

15) J. Doussiere, A. Sainsard-Chanet and P. V. Vignais, Biochim. Biophys. Acta, 548, 236 (1979).

16) M. G. Sheperd, C. Moi-Chim and P. A. Sullivan, Arch. Microbiol., 116, 61 (1978).

17) B. Maresca, A. M. Lambowitz, G. S. Kobayashi and G. Medoff, J. Bacteriol., 138, 647 (1979).

18) K. Kirimura, K. Kumagai, S. Morisada, S. Kawabe and S. Usami, Hakkokogaku, 62, 127 (1984). 